Mawdsley, E., D. Mehra, and K. Beazley. 2009. "Nature Lovers, Picnickers and Bourgeois Environmentalism." Economic and Political Weekly 44 (11): 49-59.

MCGM. 2014. Development Plan for Greater Mumbai 2014-2034. Preparatory Studies, SCE-India.

MfSGNP. 2012. A Forest Department and Centre for Wildlife Studies Collaborative Project to address Human-Leopard Conflict in and around Sanjay Gandhi National Park. Mumbai. http://mumbaikarsforsgnp.com/docs/final_report_mumbaikars_for_SGNP_project.zip, accessed July 16, 2016.

Migot, P., and M. Roué. 2006. "La gestion de la faune sauvage: une approche interdisciplinaire, une demarche adaptative." Natures Sciences Sociétés, supp. 1: 1-2.

Mitchell, T. 2002. Rule of Experts: Egypt, Techno-Politics, Modernity. Berkeley, University of California Press.

Pouchepadass, J. 2012. "Foreword." In Nature, Environment and Society, edited by N. Lainé and T. B. Subba, ix-xvi. New Delhi: Orient Blackswan.

Rademacher, A., and K. Sivaramakrishnan. 2013. "Introduction." In Ecologies of Urbanism in India. Metropolitan Civility and Sustainability, edited by A. Rademacher and K. Sivaramakrishnan, 1-41. Hong Kong: Hong Kong University Press.

Saglio-Yatzimirsky, M. C., and F. Landy, eds. 2014. Megacity slums. Social Exclusion, Space and Urban Policies in Brazil and India. London: Imperial College Press.

Sukumar, R. 1994. "Wildlife-Human Conflict in India: An Ecological and Social Perspective." In Social Ecology, edited by R. Guha, 303-17. New Delhi: Oxford University Press.

Swyngedouw, E. 2009. "The Antinomies of the Postpolitical City: In Search of a Democratic Politics of Environmental Production." International Journal of Urban and Regional Research 33(3): 601-20.

Trzyna, T., ed. 2014. Urban Protected Areas: Profiles and Best Practice Guidelines. Best Practice Protected Area Guidelines Series No. 22. Gland: IUCN.

Vaquier, D. 2010. "Impact of Slum Resettlement Projects on Urban Integration through Access to Employment: The Case of Chandivali, Mumbai." Occasional Paper 26. New Delhi: Centre de Sciences Humaines.

Wolch, J. 1998. "Zoopolis." In Animal Geographies. Place, Politics and Identity in the NatureCulture Borderlands, edited by J. Emel and J. Wolch, 381-404. New York: Verso.

Zérah, M. H., and F. Landy. 2013. "Nature and Urban Citizenship Redefined: The Case of the National Park in Mumbai." Geoforum 46: 25-33.

\section{Hong Kong's Artificial Anti-Archipelago and the Unnaturing of the Natural}

Andrew Toland

\section{The Billionaire's Island(s)}

Jules Verne's (1895) L'Île à helice (The floating island) describes a gigantic artificial island, 2,250 hectares in size, constructed by a private corporation, financed by a stock float, and populated by millionaires. It travels the waters of the Pacific Ocean, charting a climatically defined course to ensure a perpetual summer. It has a town hall and an observatory, its own water supply and highways, harbors and ports, plantations and pleasure gardens, hotels, mansions, a municipal police force, markets, cemeteries, hospitals, and schools. It is, in other words, a complete metropolis. The idea of a floating city of millionaires has become an unremarkable trope by now. There are periodic schemes for giant floating structures designed and marketed for the express purpose of operating as mobile offshore tax havens for the mega-rich. ${ }^{\prime}$ This chapter, however, traces a different and somewhat more mundane (although perhaps not entirely less fantastical) set of proposals for another kind of billionaires' artificial island, or a series of them, that emerged in Hong Kong in the late 1980s. What characterizes these schemes is not the idea of constructing an artificial island as an enclave for the exclusive habitation of the ultra-rich, but the manufacturing of an idea, as much as a physical island, to serve the purposes of a complex set of ambitions playing out in fields as diverse as geopolitical intrigue, late-colonial domestic politics, a monopolistic desire for windfall profits, long-term rent-seeking, private dominance of urban and regional infrastructure, and, finally, an attempt at an unconscious restructuring of the intercultural formation of nature(s) and landscape as they have emerged in Hong Kong.

A similar set of ambitions has recently been revived by the Hong Kong government itself, promoted by the current chief executive, Leung Chun-ying, himself a multimillionaire former property executive. These schemes, in the particular context of Hong Kong, reveal the complex interplay between Hong Kong's power structures

1. The most recent of these is the so-called Freedom Ship: see http://freedomship.com/ (accessed January 7 2015) 
(its tycoons and trading houses [hongs], its colonial and postcolonial governments and bureaucracies, its British and Chinese sovereign masters), the territory's peculiar topography and demographic and urban trajectory, and the distinctive manifestation of these currents in radical infrastructural modifications (or proposed modifications) of its environment. What emerges is a realization that histories of urban ecologies may not be confined to what has actually happened, but may also need to take account of the projected, the speculated and the imagined. The government's current proposal to build an entire metropolis on an artificial island may or may not be realized, but an appreciation of the processes involved in the scheme and its precursors gives us new insights into the dynamics in operation.

These schemes play a role in the formation of an "infrastructural imaginary" which permits the shaping and reshaping of landscapes particular to Hong Kong. However, this realm extends beyond using large infrastructural projects to structure and restructure national or regional identities, or to buttress ideologies of progress and development. ${ }^{3}$ Projected or imagined infrastructures may also be deployed as part of intricate geopolitical maneuverings or attempts to reorder a spatial condition, formed largely as the product of topographical realities, into one that is seen as more economically and, especially, politically conducive. We must also consider the background to all of this in the continual construction and reconstruction of "nature" as a cultural category, particularly in a setting where Western and Chinese constructions of this category are both in operation.

There is also another history of fantastical artificial islands that is relevant here; this one Chinese in origin. One part of the "geography" of ancient Chinese cosmology includes the islands of the immortals, which were believed to lie off the Chinese coast, just beyond the horizon (Fokkema 2011, 92). Around 100 BCE, the Emperor Wu commenced construction of the Jianzhang Palace complex, which included an artificial sea featuring reconstructions of these four islands of the immortals. These artificial islands were said to be so lavish and elaborate that the emperor harbored the wish that the actual immortals might be attracted there, and he might meet them to gain the elixir of life (Ledderose 1983, 168-69). Subsequent emperors continued to construct similar lakes with their own interpretations of the artificial islands of the immortals. It would be trite to claim Hong Kong Chinese tycoons and chief executives as latter-day emperors, but at the very least they share a cultural identity that includes a sense of continuity with the prestige of classical traditions of the scholar-merchant

2. 'Ihroughout this chapter, I use the term "imaginary" in the sense deployed by Benedict Anderson (1983) and Charles Taylor (2004)

3. Anthony Acciavatti's chapter in this volume gives a parallel example of how an infrastructure at the very opposite end of the spectrum of scale, the micro-infrastructure of the tubewell, can also opcrate similarly to reorganize urban formations and entire territories. classes throughout Chinese history. ${ }^{4}$ I am also not suggesting that the imperial history of artificial islands was even in the minds of any of the contemporary protagonists in this story. The relevance of these histories is as a reminder that ideas and attitudes to culture and nature in Hong Kong are a complex amalgam, and that the outlook that shapes or seeks to shape land and sea in the territory, if only at a subconscious level, draws on a highly particular set of imaginaries.

\section{Hong Kong: Seminal Urban Ecological Problematic and the Puzzle of Hong Kong "Nature"}

Before describing these particular schemes in detail, it is worth briefly outlining the significance Hong Kong has had in the history of studies of urban ecology, particularly in the strand of the field originating in the natural sciences, in biology and in ecology studies. In his background essay on "The Analysis of Cities as Ecosystems" in the Routledge Handbook of Urban Ecology, Ian Douglas $(2011,21)$ discusses the emergence of the study of urban ecosystems as part of the UNESCO Man and the Biosphere Programme, and in particular the case study work on Hong Kong. In 1974, UNESCO brought under its auspices the Hong Kong Human Ecology Programme, a collaboration between the Australian National University, the University of Hong Kong, and the Chinese University of Hong Kong, as the first pilot project in its Man and the Biosphere Programme, designed to promote integrative ecological studies on human settlements (Boyden et al. 1981, xv). The findings of this study were published under the title The Ecology of a City and Its People: The Case of Hong Kong (Boyden et al. 1981). One of the notable features of this work is its early attempt to map biophysical changes in the urban environment against a particular cultural background. The first substantive chapter on Hong Kong thus contains an attempt to address the implications of the effects of "traditional Chinese and modern Western cultures for the ecological situation" in Hong Kong:

During the past twenty years, the environmental changes in Hong Kong have been spectacular, as it has developed into the major manufacturing and commercial centre that it is today. The "economic miracle" of Hong Kong has involved the ever-increasing use of machines powered by extrasomatic energy, ever-increasing levels of air and noise pollution and ever more displacement of natural vegetation by concrete. No effort has been made to preserve substantial areas of parkland in the city. The observer is left with the impression that any ideas about harmony with nature, which are so important in Chinese philosophy, must have been very far from the minds of all those involved in bringing about these changes....

\footnotetext{
4. The cultural practices and belicfs of the immediate forebears of the current Hong Kong tycoons and political
} class in the second half of the nineteenth century are discussed in Sinn (2003). 
What is the explanation for this apparent paradox? Can it be that all this emphasis in Chinese philosophy about harmony with nature is mere empty words, and has no meaning when it comes to practical matters? Our own view is that the confusion probably lies in our use of the word "nature". (Boyden et al. 1981, 46-47)

Puzzlement over this apparent paradox or contradiction amongst non-Chinese scholars has not dissipated over the intervening years. Sinologist Wolfgang Kubin $(2010,516)$, for example, writes of the tension between the persistent discourse of "harmony" between people and nature in both Chinese classical texts and contemporary everyday Chinese-language discourse and the evident destruction of natural environments in mainland China, Hong Kong, and Taiwan. Kubin asks, "How do we explain this obvious contradiction, especially when we face the fact that money has a priority that dominates both nature and culture?" Certainly, as Boyden et al. and Kubin acknowledge, a significant part of this apparent contradiction is dissolved when the multifaceted and historically layered concepts contained in the Chinese words and phrases translated into English as "nature" or "landscape" are better appreciated. At this level of comparative philology and philosophy, saying that nature is culture is an unremarkable truism. Nevertheless, another more contemporary aspect of the relationship between this conceptual domain in both cultural traditions and the biophysical realities it maps bears examination. One concrete way that this can be observed playing itself out is within the "infrastructural imaginary" of Hong Kong as it has been deployed by local elites in what might be thought of as a contest over "topographical identity," in the sense of the projection of a hypermodern future, where even the very ground on which the city is founded can be artificially created and granted a radical autonomy from the patterns and constraints of the preexisting metropolis.

\section{Gordon Wu's Artificial Island(s)}

To understand the context in which Hong Kong's first private scheme for a large-scale artificial island emerged, one has to untangle the knot of economic, infrastructural, geotechnical and geopolitical pressures that had built up over time in relation to one of the key infrastructures that umbilically connected the colony of Hong Kong, marooned on the shores of a menacing and unstable Communist China to the rest of the "free" world: its commercial airport. Like Cold War Berlin, and despite Hong Kong's historical and continued (indeed, rapidly expanding) role as a shipping center, in the postwar decades, its airport was the key symbolic and actual link between Hong Kong and the evolving networks of the global economic and political order. From the end of the Second World War onwards, despite continuing to enlarge and develop it over the subsequent three decades, the Hong Kong government held the view that the site of the original commercial airport at Kai Tak was ultimately unsuitable. Those three decades were thus also punctuated by periodic departmental studies and consultancy reports searching out alternative sites for a new airport. By 1978, the government was beginning to focus on the idea of reclaiming land around the small island of Chek Lap Kok off the northern coast of Lantau, Hong Kong's largest island. Over the next five years a plethora of studies and reports were produced, only for the scheme to be put on hold at the start of 1983 as a result of the government's deteriorating financial position (Hong Kong Government 1991, 23-31). This, in part, was the result of a currency crisis triggered by the announcement in September 1982 that China and Hong Kong would be commencing diplomatic negotiations about the future of Hong Kong's sovereignty (Yao 2001, 30). The creation of artificial land, geopolitics, individual and collective anxieties, and the fluctuations of financial markets thus all form part of the background to this projected urban infrastructure.

Once the crisis had passed, another layer was added; by the mid-1980s, the effects of the growth in the re-export trade resulting from Deng Xiaoping's 1979 economic reforms and the special economic zones created in the Pearl River Delta began to strain the capacity of Hong Kong's port infrastructure. In mid-1986, the government announced it was considering the construction of an artificial island inside Hong Kong harbor to serve as an additional cargo terminal, inspired by an artificial island built for similar purposes in Kobe, Japan (South China Morning Post 1986a). Thus, by mid1986, two government-initiated proposals for artificial islands were afloat in the space of policy and planning speculations in Hong Kong: one for an artificial airport island, and another for an artificial port island. ${ }^{5}$

It was against the background that, in November 1986, Gordon $\mathrm{Wu}$, a property, construction and infrastructure tycoon, revived the dormant issue of a new Hong Kong airport by suddenly presenting the colonial government with a proposal for a giant artificial island in the waters west of Hong Kong Island and east of Lantau Island in an area that has now become known as the "central waters." Although Wu was the originator of the idea, his proposal was issued under the names of three other Hong Kong conglomerates in addition to his own development company, Hopewell Holdings Limited. These were Cheung Kong (Holdings) Limited and Hutchison Whampoa Limited, both controlled by Wu's fellow tycoon, the immensely powerful and influential Li Ka-shing (for decades, especially before the recent rise of mainland Chinese billionaires, perennially referred to as the richest person in Asia).

5. Both these developments in fact raise the issue of the influence of large-scale lapanese state-sponsored infriastructure and engineering projects on the policy and planning landscape of Hong Kong. In addition to the precedent provided by Port Island in Kobe, constructed between 1966 and 1981, by the mid-1980s, significant international attention was focused on the plan for Kansai International Airport, constructed on a large artificial island in Osaka Bay. 
Wu was a Princeton-educated engineer who made his initial fortune through Hong Kong property development, but built his reputation amongst Hong Kong's tycoons around the huge infrastructure projects his companies built, especially in southern China, most notably power stations and toll-road superhighways. The influence of both $\mathrm{Wu}$ and, in particular, Li in Hong Kong rested on their history and the scale of their land holdings as developers and landlords throughout the city. Although Wu's initial November 1986 proposal did not propose a giant artificial island, it conceived of a colossal integrated infrastructure project involving a new airport, port facilities and road system in the central waters. ${ }^{6}$

In January 1987, the Wu-Li consortium issued a public "Fact Sheet" (Hopewell Holdings et al. 1987, 1, 3). The Fact Sheet attached three different maps (Figures 8-11) illustrating the schematic design of three alternative configurations for the project. The first (Figures 8 and 9) adopted the government's published but then-shelved plans for a new airport at Chek Lap Kok (which were similar to the new airport that was ultimately realized between 1991 and 1998). This scheme did not involve the creation of a significant autonomous artificial island; it was principally achieved by augmenting existing islands through significant reclamation. However, in addition to the government's existing design for the new airport, which involved the levelling of and large-scale reclamation adjacent to the islands of Chek Lap Kok and Lam Chau, the consortium's "Scheme A" proposal involved substantial linear tracts of reclamation to create deep-water port berths, largely along the northern and north-eastern edges of I antau, the eastern sides of Ma Wan and Kau Yi Chau Islands, and on a severely rectilinear artificial island attached to one of the connecting highways between Lantau and Hong Kong Islands. From an urban perspective, what is notable about this scheme-and a feature given very little attention in the accompanying text-is the substantial reclamation for "housing" created by the reclamation in the water between Peng Chau and Hei Ling Chau islands: a reclamation that from the schematic drawing looks as if it would have created almost as much urban land as the then-existing built area along the northern waterfront of Hong Kong Island, or a significant part of the Kowloon Peninsula. This, together with the proposed reclamation on the western tip of Hong Kong Island out to Green Island, again earmarked for urban housing, would have created extremely large and valuable "land banks" of developable urban land for the benefit of the private consortium. Schemes B (Figure 10) and C (Figure 11)-the alternatives preferred by the consortium-were even more ambitions, combining ports, airport, industrial land, and housing into a giant flat megastructure, dominating the waters between Lantau and Hong Kong Islands, at the kind of scale that perhaps would have made it Hong Kong's largest contiguous built urban area. Wu's scheme further involved the construction of a bridge and highway toll-road system

6. Conf usingly, the area that the earlier schemes described as the western harbor is the area that is now referred to as the central waters. I have used the most recent term, "central waters," to refer to this same area throughout.

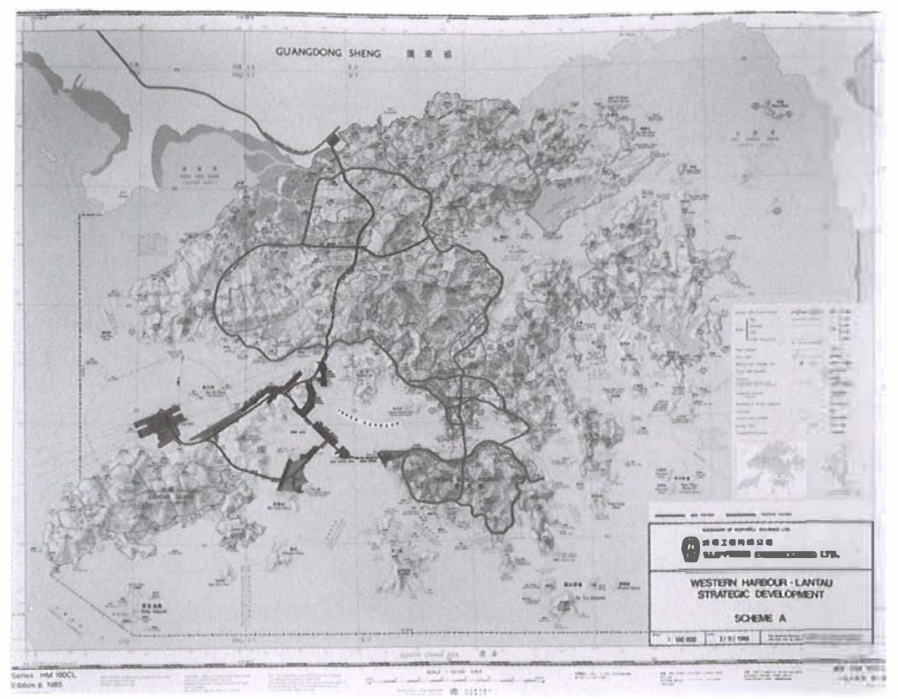

Figure 8

Gordon Wu's January 1987 artificial island proposals.

'Territory scale map of the consortium's "Scheme A," incorporating the government's earlier proposals for the new airport at Chek Lap Kok, new deepwater port berths along the northern and north-eastern edges of Lantau Island, and an additional artificial island predominantly for housing in the central waters between Lantau and Hong Kong Islands. 'The map also shows the connecting infrastructure of bridges, tunnels and tollways linking Hong Kong to Shenzhen, across the border with China. Original color photograph attached to Hopewell Holdings et al. (1987). Courtesy of Hopewell Holdings Limited.

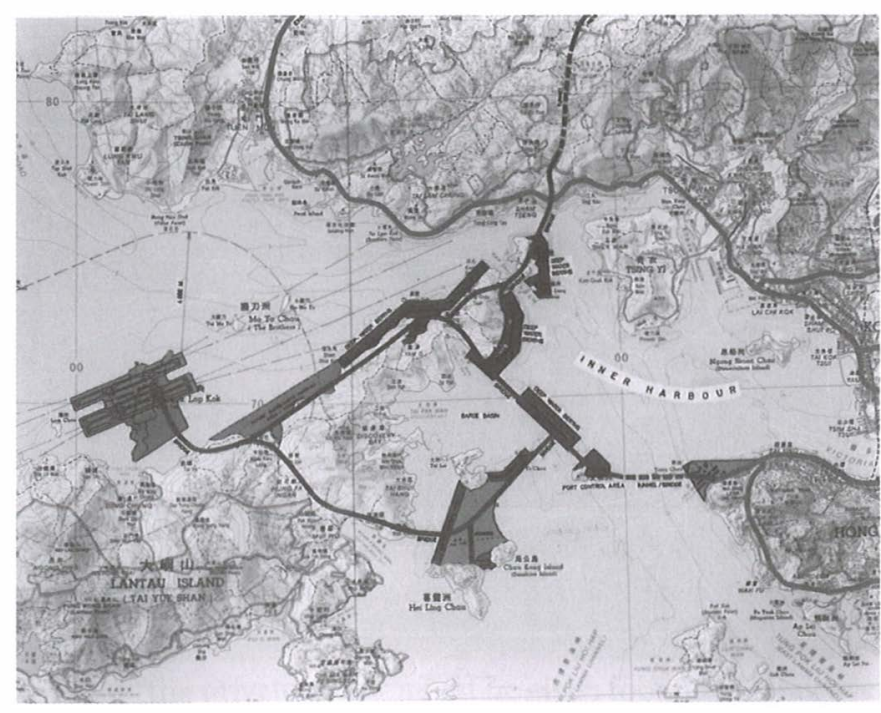

Figure 9

Gordon Wu's January 1987 artificial island proposals.

Detail of "Scheme A." The artificial island with large areas for new housing (which appears as a lighter gray) between Hei Ling Chau, Chou Kung, and Peng Chau islands. Original color photograph attached to Hopewell Holdings et al. (1987). Courtesy of Hopewell Holdings Limited. 


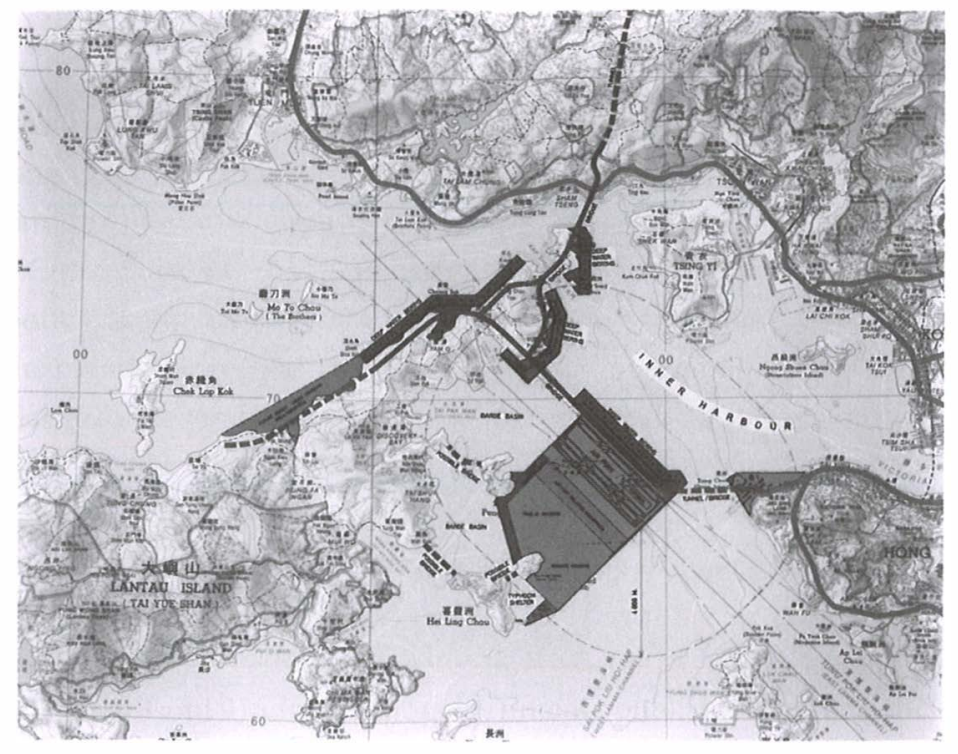

Figure 10

Gordon Wu's January 1987 artificial island proposals.

Detail of "Scheme B." Airport, port and auxiliary infrastructures, and large areas of public and private housing are combined into a single giant artificial island. This is the scheme creating the largest area of land developable for housing. Original color photograph attached to Hopewell Holdings et al. (1987). Courtesy of Hopewell Holdings Limited.

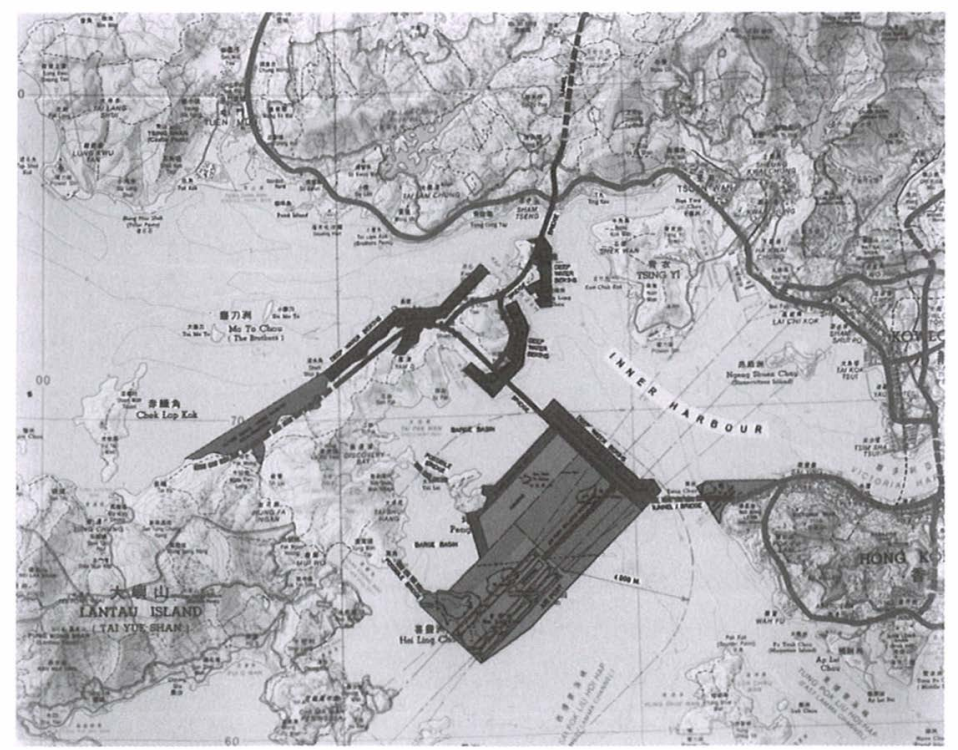

Figure 11

Gordon Wu's January 1987 artificial island proposals.

Detail of "Scheme C." Airport, port, auxiliary infrastructures, and housing are again combined into a single giant artificial island, with a different orientation for the airport runways. Original color photograph attached to Hopewell Holdings et al. (1987). Courtesy of Hopewell Holdings Limited. connecting these new infrastructural territories with Hong Kong Island, Kowloon, Lantau, and Shenzhen, across the border in China. The bridges and roadways would also host shipping berths, but the centerpiece of the proposal, simply because of the sheer scale of its ambition, was the construction of the new airport and housing areas on an artificial island east of Lantau in the central waters.

Although the consortium had persuaded the Hong Kong government to set up a joint working group to study the proposal, the two parties did not hold identical views. The Chief Secretary of the British colonial administration, David Ford, indicated the government's desire for a "phased approach," whereas Wu's position was for the project to be treated as an all-at-once totality. Wu was also insistent in pointing out that his scheme had the backing of Hong Kong's other tycoons and hongs-in addition to Li Ka-shing's Hutchison Whampoa and Cheung Kong companies, Wu had by this stage persuaded Jardine Matheson and the Swire group to back his proposal.? More significantly, $\mathrm{Wu}$, in his statements in the media, continually and very strongly implied that his scheme had the blessing of Beijing (Altink 1987). Wu ensured that the lobbying of the Hong Kong government by private corporate interests intensified. In June 1987, his company, Hopewell, upped the ante when its executive director, Stewart Elliot, gave an interview indicating that further influential Hong Kong conglomerates, namely the Hongkong Bank group, and the Sir Y. K. Pao group, had also joined as potential investors. He also asserted that several mainland Chinese state-owned corporations and agencies-CITIC, China Resources, the Guangdong Provincial Government and the Bank of China-were also backing their scheme, as was Xu Jiatun, China's unofficial "ambassador" in Hong Kong, whom Elliot reported had met with Wu and Li Ka-shing the previous December and told them: "China is solidly behind this project" (SCMP 1987). Wu also succeeded in driving a wedge between the British government in London and the local British colonial administration. Media reports on funding by the British Department of Trade and Industry for the feasibility study on the new Hong Kong airport suggested the department was ignoring the reservations of the Hong Kong government and backing Wu's scheme because of the potential benefits to British-based engineering companies (Murray 1987). Elliot also claimed that he had been told by Percy Craddock, Margaret Thatcher's chief foreign policy adviser, at a meeting at 10 Downing Street, that Hopewell's proposal had "the Thatcher cabinet's 'full moral support"' (Roy 1989). Even within the Hong Kong government, the scheme, and the intense pressure Wu and his corporate partners were exerting, appeared to be causing rifts amongst senior officials. On the one hand, some officials feared that "the private sector might be given too much sway over long-term transport policies" (SCMP 1988), while other senior officials were quoted as insisting, "We need a big infrastructure project for corporations to park their funds" (Ng 1987).

7. Jardine Matheson and the Swire Group were Hong Kong conglomerates that had evolved out of the old British colonial trading houses - the "hongs", from the Cantonese word for trade or business organizations. 
There were also reports that Wu had persuaded the Chinese State Council to approve and publicize the construction of a new Shenzhen airport in order to put pressure on the Hong Kong government to support his scheme (Harte and Fong 1987). Wu had thus succeeded in transforming a highly speculative infrastructure and urban development proposal into a multi-dimensional contest between the Hong Kong colonial government, the British and Chinese governments, and the most powerful business interests in Hong Kong. Ultimately, it would appear that what was at stake for Wu was the prospect of lucrative windfall profits from control over the vast areas of developable land that could be created by the reclamation: the quid pro quo for Hopewell and Cheung Kong building the airport using private capital was the grant of property concessions with respect to the land (SCMP 1988).

The broader stakes for Hong Kong tycoons should also not be forgotten. By the early 1990s, Hong Kong was rapidly becoming the location of the world's then-most expensive commercial and residential real estate (Warren 1994). Hong Kong had the world's largest container port in terms of throughput volumes (FEER 1987). Both Wu and his steadfast partner throughout his attempts to realize his ambitious artificial island scheme, Li Ka-shing, as well as almost every other Hong Kong tycoon, were concurrently developing lucrative and complex economic interests on the mainland. At the same time, they were uncertain about the looming handover, and its potential effects in the financial and property markets and on their wealth holdings and investment interests. Unlike for the late-colonial administration, for the tycoons, the distinction of the border seemed to both matter and not matter. They had interests on both sides. Although there were fears of a threat to Hong Kong's ports from mainland competition, and Li Ka-shing's Hutchison Whampoa was the major operator of the Hong Kong ports, his companies were also leading the consortium developing the huge Shenzhen port that would be its main immediate rival (Torode 1993). In addition to the prospect of controlling large and highly profitable land holdings in Hong Kong, the other attraction for Wu of the artificial island mega-project, and the extensive transportation infrastructure projects it entailed, was that it offered him the prospect of seamlessly integrating a new set of Hong Kong toll roads into the extensive network of superhighways he was already constructing across the entire Pearl River Delta.

Eventually, in 1991, the colonial government made the decision to go ahead with the construction of a new airport at Chek Lap Kok along the lines of its original plan, rejecting Wu's proposal, although not without feeling the need to issue a detailed critique of his scheme (HKG 1990). Wu was not prepared to concede defeat and embarked on a new round of lobbying in favor of his scheme. In 1991 he gave an address at a public seminar discussing alternatives to the new airport proposal in which he again set out his case for an artificial island (to include an airport and port facilities) in the central waters (Wu 1991). In addition to his claims about the superiority of this siting for the new airport, $\mathrm{Wu}$ asserted that an artificial island in the central waters represented "an ideal place to build the next new town for our children in the 21 st Century" (Wu 1991, 6). Wu's main argument was that his scheme was crucial to protecting Hong Kong's future, and that only he had the contacts within and understood the thinking of the mainland authorities in order to protect Hong Kong's interests under the sovereignty of its new masters. Wu cited further discussions he had had the previous month with senior Chinese officials and reiterated that his scheme still "[had] their . . blessing." He concluded by emphasizing that these high-level connections, and his extensive experience in pitching huge infrastructure projects in mainland China meant that he could "deliver Beijing's support for Hong Kong should the need arise" (Wu 1991, 12).

Despite the rejection of his port-airport-real estate proposal, Wu did not give up on his schemes to create new developable land through the construction of large artificial islands. In 1999, after the handover, he persuaded the new Chief Executive, Tung Chee-hwa, yet another of Hong Kong's tycoons, to commence a study into an ambitious proposal to reclaim 10,700 hectares of land in shallow-water bays and "the creation of an artificial island, twice the size of [the airport at] Chek Lap Kok, that would engulf Peng Chau and Hei Ling Chau, to house 3.6 million people" (SCMP 1997) (Hong Kong's total population at the time was 6.5 million). By this time, however, with the new airport completed, Wu had turned his main focus to lobbying for a new privately funded mega-inf rastructure project-a twenty-nine-kilometer bridge connecting Hong Kong, Macau, and the Chinese city of Zhuhai across the open water at the mouth of the Pearl River Delta (Cheung 2003). Wu agitated for a 50 percent ownership stake in the bridge (Tsang 2003), which would have cemented his companies' dominance of the regional road infrastructure. Although his idea for the mega-bridge was taken up, his bid to construct it entirely with private capital under his direction ultimately failed; responsibility for the scheme, as well as the construction costs, were split between the Hong Kong, Macau, and mainland governments.

\section{East Lantau Metropolis}

Wu's 1980s scheme is now finding a contemporary echo in a recent government proposal for an "East Lantau Metropolis." In his Policy Address on 15 January 2014 to the Hong Kong Legislative Council the Chief Executive, Leung Chun-ying, announced that the government would:

explore ways to further develop the eastern waters off Lantau Island and neighbouring areas, with a view to developing an East Lantau Metropolis for accommodating new population. It will become a core business district in addition to Central and Kowloon East for promoting economic development and providing job opportunities. (Leung 2014, 12) 


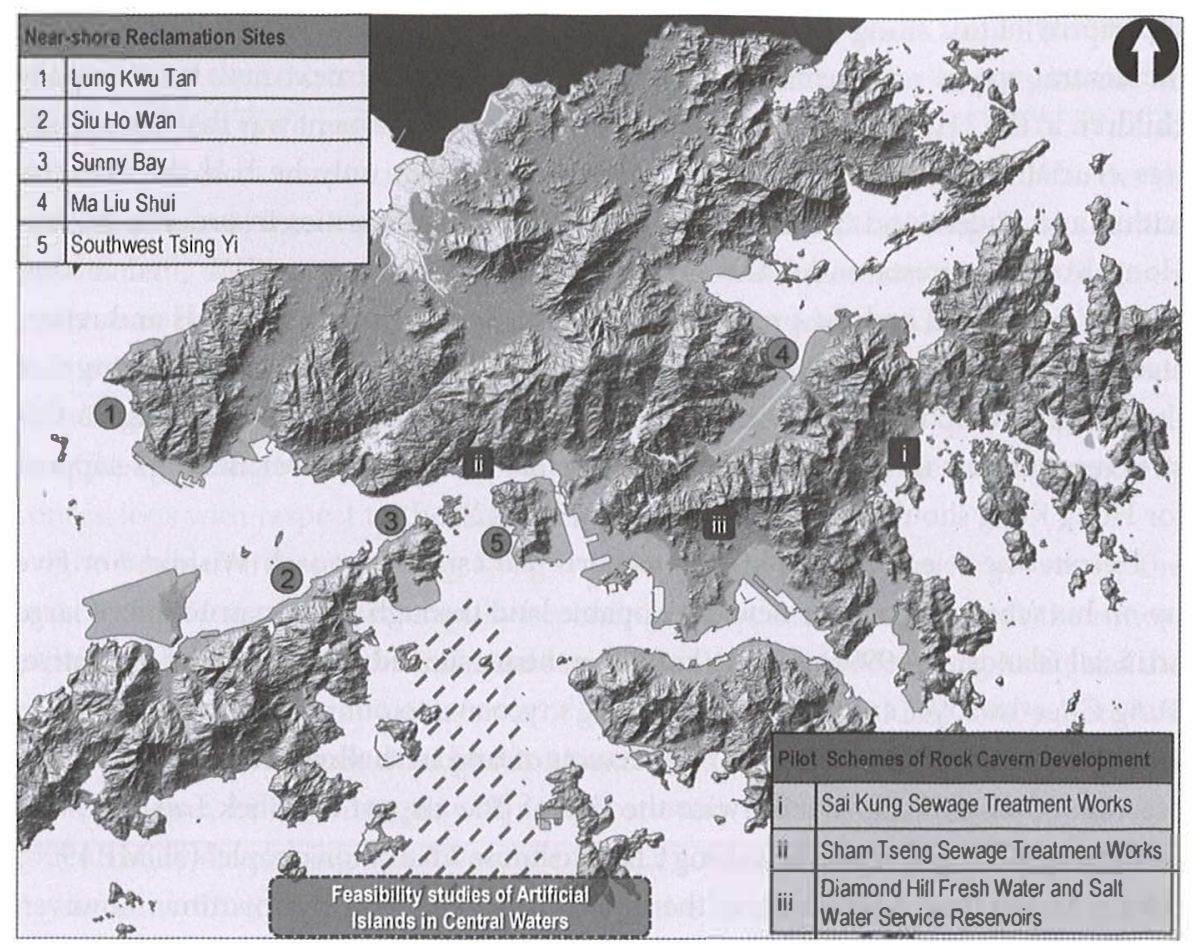

Figure 12

C. Y. Leung's East Lantau Metropolis proposal.

The cross-hatched area shows the zone being considered for the artificial island(s) on which the East Lantau Metropolis could be built. No more concrete detail of the form or size of the island has yet been made publicly available by the government. Map attached as "Figure 1" to the Advisory Council on the Environment Paper No. 3/2015, March 9, 2015, "Enhancing Land Supply Strategy: Reclamation Outside Victoria Harbour and Rock Cavern Development." ACE is a permanent non-statutory body charged with keeping the state of Hong Kong's environment under review, and advising the government on environmental protection. Courtesy of the Port Works Division, Civil Engineering and Development Department, Hong Kong SAR.

Leung provided very little detail about this scheme; ${ }^{8}$ only much later on in the address did he indicate the proposal actually involved building the East Lantau Metropolis on an artificial island rather than further reclamation of the east coast of Lantau Island (Leung 2014, 44-45). He gave no indication of its proposed scale, but in its reporting on this aspect of the address, South China Morning Post, citing a government source, reported that it could be "similar in size to the city's airport island" (Li and Wong 2014), the 1,225 hectare reclamation created by levelling and extending Chek Lap Kok and Lam Chau islands of the northern coast of Lantau. Few concrete

8. Very little concrete information is publicly available overall. The vagueness seems intentionally designed to deflect criticism. Even illustrations of the scheme contain only the haziest outlines, literally (see Figure 5). details have been released by the government in the intervening period, although Leung reiterated his commitment to the scheme in his 2015 Policy Address (Leung $2015,24-25)$. What has emerged is that the strategic dimension of the scheme envisaged by the government, and also the Lantau development lobby, involves shifting Lantau's status from that of an "outlying island" of Hong Kong to a central role, both geographically and economically. The proposal aims to capitalize on the Hong KongZhuhai-Macau bridge (now nearing completion) in connecting the western side of the Pearl River Delta, where Zhuhai, Macau and other secondary areas "with rich resources and enormous ... development potential" are located, with the eastern side of Hong Kong and Shenzhen, and also tying in the new third runway being planned for Hong Kong's airport. In Leung's account, this would make Lantau, "the converging point of traffic for Guangdong, Hong Kong and Macao" (Leung 2014, 11-12) and permit Hong Kong "to attain synergy with the Greater Pearl River Delta development" (Leung 2015, 27).

Once again the speculative figure of a giant artificial island or islands is being deployed within Hong Kong's infrastructural imaginary by its political and business elite. The consequences of these maneuverings, however, do not stay merely political or economic. From this point, we may now begin to trace their more subtle workings within the hybrid formations of Hong Kong's natures-cultures.

\section{(Political) Topographical Historiography}

The decade bracketing either side of the Hong Kong handover was a particularly fertile period for scholars in the humanities engaged in a reevaluation of Hong Kong's cultural identity. Much of this work focused on the conditions and experiences that had arisen as a result of the intensity of its urbanization, in combination with the particular tensions, anxieties and atmospherics produced by the colonial to postcolonial transition. Never far away from these investigations were the effects of the peculiar "nature" of Hong Kong-the ever-present water of its coastal geography of bays and inlets, its long history of aggressive harbor front reclamation, its ungainly mountainous terrain, all interacting to constrain, shape and deform the insatiable development drives of its political leaders and bureaucrats, hongs and tycoons, and in the process creating a distinctive form of urban nature. In a 2003 paper, Jeremy E. Taylor suggested that a new type of historiography had emerged within local, primarily Cantonese-language history and literary writing that positioned the territory, not primarily as a Chinese city (whether viewed in terms of sovereignty or ethnic composition), but in terms of its distinctive features of locality and topography (Taylor

9. In this context-topographical historiography and topographical writing-the word "topography" is used in its broadest and most etymologically pure sense, deriving directly from the Greek toroypá $\phi o c$ one skilled in describing or delineating a particular locality. 
$2003,45,52)$. At a superficial level, this dovetails with the persistent governmental and business discourse within Hong Kong that continually asserts its status as a "world city." Taylor $(2003,70)$ took his cue from an article published by Chen Dawei (2000) in the Chinese literary journal Xianggang wenxue (Hong Kong literature). Chen had identified what he described as a genre of "topographical writing" (地誌 書寫 dizhi shuxie), which focused on the specifics of the territory's built environment and the geographic reality of the city's compressed density between "mountain and water" (the Chinese ideograms for mountain and water form the two components of the Chinese word-compound for classically describing what in English is translated as "landscape" - shanshui (U!水) - and form the basis of the long tradition of Chinese aesthetic landscape theory and practice in painting and poetry, not to mention moral philosophy and metaphysics, that grows out of this dualistic pairing). Although Chen's observations focused on writings, especially poetry, about Hong Kong's vernacular urban environment and the emergence of a certain kind of urban landscape writing, Taylor's interpretation was that this spatial orientation of popular history and literature in Hong Kong represented a unique form of "topographic historiography." The import of this interpretation is that those involved in shaping the discourse of Hong Kong's cultural identity deliberately chose to emphasize "place" rather than "people" as a tacit political strategy. This continues to provide a useful starting point for developing an understanding of urban environments and their sociocultural significance in Hong Kong. Chen's and Taylor's analysis of emerging Hong Kong post-handover identity draws attention to the specific way in which Hong Kong's landscapes have been used to serve the formation of a nature-culture identity discourse rooted in place rather than people: a topographical imaginary.

The deliberate orientation away from the fraught issues of sovereignty, Chineseness, and the representation of Hong Kong as a unique example of Chinese urban modernity, allows us to gain an understanding of the particularities of Hong Kong's experience that sets up a spatial counter-history to the more conventional accounts of Hong Kong's urbanism and economic development. Yet Taylor's piece (published in 2003) and Chen's essay (published in 2000) should be recognized as having been conditioned by the particular anxieties of the immediate pre- and post-handover periods within Hong Kong's cultural and intellectual milieu. The idea of a topographical historiography is deliberately counterpoised to the state-mandated "patriotic historiography" (愛國史學 aiguo shixue) that emerged on the mainland in the lead-up to 1997 (Taylor 2003, 50). It evinces a desire to reject "biology" (in the crude, social-Darwinian, race-based sense in which British colonial and Chinese nationalist writers were perceived to be deploying it), and instead embrace Hong Kong's urban geography as a source of meaning, identity, and significance. Topographical historiography, then, serves to direct attention towards place and location as a central quality of "Hong Kong-ness."
Most examples of the genre are self-consciously nostalgic and overwhelmingly urban in their orientation. However, one well-known work that also falls within the genre of topographical historiography (although it is not specifically referred to by Taylor) is Dung Kai-cheung's (2012) Atlas: The Archaeology of an Imaginary City. Published in Chinese in 1997, and written in the years leading up to the handover, it shares many of the same themes as the more vignette-based work described by Taylor. However, its topographical scope is much broader, ranging across the entire territory of Hong Kong. In the chapter titled "Chek Lap Kok Airport," Dung narrates a kind of critical fantasy evolved by "the sharp eyes of scholars of strategic cartography" upon inspection of the blueprints for the new airport island. In this imagining (a latter-day L'̂̂le à helice perhaps):

The original concept was to separate a section of the surface of Hong Kong Island from the earth's crust and install a huge propeller on it, converting it into a mobile port, but this plan was later abandoned because the size of the project made it unfeasible. Mobility had all along been the central concept in the contingency strategy, because in a city that lacked the ability to defend itself in every respect, escape was the only way out in the event of disaster. (Dung 2012, 130; emphasis added)

It seems that Dung's strategic cartographers were not the only ones to see an artificial island as an escape strategy. On July 4, 1989, the one-month anniversary of the Tiananmen Square massacre, the South China Morning Post published a letter (Irby 1989) advancing a "solution for the people of Hongkong . . . [in the form of] the construction of an artificial island, sufficient to their needs, with sovereignty" to effect "a transplanted free Hongkong."

Contra these fantasies of novelists and newspaper letter-writers, scale has not been seen as a barrier to the $\mathrm{Wu}$ and Leung artificial island schemes, and the contingency strategy is not one of escape, but rather a movement in the opposite direction, for tighter integration with the mainland. We might speak of another kind of topographical historiography to the one found in the writings of novelists and poets; one that focuses more on the large-scale nature-culture assemblages that also characterize Hong Kong's infrastructural imaginary: the monumental planning projects on reclaimed land; the forests of tower blocks and the resulting "wall effect" created between harbor and mountain ${ }^{10}$ (in effect, what amounts to the construction of an artificial mountain range); and the levelling of entire islands to build an airport. A topographic historiography that moves away from the small-scale and local inevitably brings back the political, but in a climate no longer so strongly conditioned by the "before" and "after" effects of the handover. In this setting-one in which

10. See, for example, Wong $(2010,326)$ 
Hong Kong-mainland dynamics are much more opaque-it seems appropriate to turn our attention once again to the political aspects of the topographical. Cast in this light, how are we to frame a contemporary interpretation of the mega-infrastructural artificial island proposed by Gordon Wu, or C. Y. Leung's recent government-sponsored version?

\section{Doubly Artificial Islands, the Anti-Archipelago, and the Unnaturing of the Natural}

To the extent that these proposals are attempts to create artificial "natures," they are doubly artificial: they require the massive financial and engineering feat of creating "land" in open water, and, at least for the time being until they are physically constructed, they involve artifice in the sense of being imaginary, projective, rhetorical-embodied only in the discourses, reports, diagrams, drawings and renderings used to make the case for them as a future reality. It is well to be reminded that topography refers to the detailed description of a particular locality and its features, and derives from the conjunction of the two Ancient Greek words topos (place) and graphia (writing or drawing). It is at this point we might productively return to the tacit cultural traditions that might vibrate just below the surface of Wu's and Leung's proposals and their various rhetorical strategies. The suggestion is not that Wu or Leung are directly influenced by classical Chinese conceptions of "nature" (or rather the various aspects of historical Chinese philosophical, moral and aesthetic thought that have been rendered into English as "nature" and its cognates in other European languages). In fact, as members of a local elite with a rigidly conventional and limited notion (albeit on a megalomaniacal scale) of the possibilities of infrastructural landscapes in Hong Kong (the history of Hong Kong is, almost from the outset, a history of reclamations [Ho 2004]), Wu's and Leung's artificial island schemes throw into relief the impossibility of a "nature" bound up with large scale modifications of environmental conditions and formations at both a biophysical and a cultural level. Or as William Franke $(2014,7)$ has put it in his discussion of the work of the French sinologist and philosopher François Jullien, the questions raised by the comparative study of representations of "nature" in China and the West, "[serve] perfectly to bring out the stakes of apophasis as a miraculous 'open sesame' in this encounter between cultures because the characteristic efforts of both cultures clearly show that, taken radically, nature is beyond all possibility of representation." The apophasis-the denial-the radical unnaturing at work in the artificial island schemes, if they can be allowed to stand as in some way representative of the infrastructural imaginary in an East Asian context, suggests that what might instead be representable or represented in these schemes is an artificial (political) topography that is a denial of both complex biophysical realities and local aspirations for a place-based Hong Kong identity oriented outwards towards the world."

In this context, we must also be attentive to the complex status of the "artificial" in relation to the "natural" in the Chinese tradition; again, not because of any direct line of intellectual genealogy, but because the long history of conceptions of an artful (artificial?) nature might allow us access to the deeper aspects at play in this infrastructural imaginary. Writing about objectivity, subjectivity and authenticity in traditional Chinese conceptions of landscape, Feng Han outlines Qing dynasty literatus Zhang Chao's (張潮, 1644-1711) theory of four layers of meaning in nature. These four layers are organized in an evolving historical progression. In the fourth stage, an internalized subjectivity of landscape developed in which "the free use of all natural materials and creative abilities for the deconstruction of nature were shown in Chinese landscape gardens and landscape paintings" (Han 2012, 96-97) Making a similar point about classical Chinese painting and poetry, Simon Leys $(2013,339)$ writes, "for a Chinese painter, the measure of success was not determined by his ability to fake reality but by his capacity to summon reality. The supreme quality of a painting did not depend on its illusionist power but on its efficient power; ultimately, painting achieved an actual grasp over reality, exerting a kind of 'operative' power." Turning to the question of "authenticity," Han $(2012,97)$ observes that within the Chinese tradition "the highest level of landscape attainment is the one inspired by great Shanshui and elevated by human culture." This "traditional" cultural element might be apparent in the way in which, in a recent interview, Chief Town Planner Winnie Lau, the government official responsible for the East Lantau Metropolis, chose to describe the project. The voiceover of an official government news video reports that "[s]he compares her work to that of an artist drawing a three-dimensional painting. But for Ms. Lau, the challenge is that her 'painting' must come to life" (HKGISD 2015).

A complexity thus arises if we wish to analyze these projects according to the concepts of the artificial and the natural, to return to the apparent contradiction that seized the attention of the researchers in the early UNESCO study of Hong Kong. It is a dichotomy that is reinforced by the very term "artificial island." However, global scientific discourses of ecologies and natural systems do not capture the subtle interplay of the cultural and the political within Hong Kong's infrastructural imaginary. If, as contemporary academic thinking has emphasized again and again, modern (western) "nature" is a flawed and problematic concept, and the complex network of words and ideas in both Chinese traditional and contemporary usage find imperfect

11. Taylor $(2003,45-46)$ points out that a feature of topographical writing was a desire by local authors to position Hong Kong amongst the "constellation of other great metropolises, from Tokyo to New York ..., as opposed to Chinese Hong Kong” (emphasis in original). 
correlations in English and other European languages, how can we even begin to usefully interpret these so-called "artificial islands"? The islands become even more un-"natural" if, at the level of intellectual inquiry, we bear in mind the scholarship of the last several decades which has worked to undo uncritical reliance on the idea of "nature": what "nature" is there for the islands to be artificial versions of? Further, if there is no neatly corresponding "nature" in Chinese language or thought (perhaps even more so in the hybrid culture of Hong Kong, with its complicated admixture of the "Western" and Chinese), and if, in any case, the most venerated "nature" intertwines landscape and human culture, are the artificial islands somehow a more authentic realization of value than their "natural" counterparts? It is into this void or apophasis that the schemes of Wu and Leung find the space to do their work of political and economic reordering at the territorial scale. ${ }^{2}$ This is a dimension of Hong Kong's projected urban nature that the global discourses represented by the UNESCO Programme and its heirs in the scientific study of urban ecology cannot capture within their models.

One of the themes of these artificial island schemes is the creation of land without (or with almost no) environmental cost (as its proponents see it)-a strategy more political than environmental, directed principally at short-circuiting the long-standing popular resistance that has built up in Hong Kong over reclamation of existing coastline. The vision of creating real estate without using actual "land" (to the extent that sand dredged off the seabed is not thought of as land), and the positioning of it as a literal island, separated from the effects of immediate adjacencies, also acts to defuse the economic conflicts that arise as property owners who once held waterfront real estate with harbor views find themselves relegated to a position further inland. It also operates as an ultimate tabula rasa; it can be any form and whatever scale required, offering the utmost "flexibility in planning" in the anodyne official language. Further, it also undoes "land" in its classical economic sense as one of the three fundamental factors of production in the triumvirate of land, labor, and capital. Like credit money, it is no longer a scarce, fixed, exogenous input, but a fungible, endogenous variable that can be manipulated according to the desire for a particular economic return or strategic political effect.

But perhaps of even more interest, is the deployment of the idea of these kinds of artificial islands in the context of Hong Kong as an infrastructural mechanism, linked to a chain or network of other infrastructural mechanisms (the Hong Kong-MacauZhuhai mega-bridge, the various regional superhighways, the ports and other logistical infrastructure) to provide as flat and frictionless an integration of Hong Kong into the Pearl River Delta as possible. If, conceptually, within contemporary critical

12. 'There is a similarity between the political functioning of "unnaturing" here and way in which Christina Schwenkel (see her chapter in this volume) writes about "greening" operating in a very different Asian context, in communist postwar Vietnam, to effiect the "unpeopling" of urban spaces. theory ${ }^{13}$, archipelagos have come to stand for a rich variability and cosmopolitanism of interactions and conditions-biophysical, linguistic and cultural-these schemes emphasize their importance in integrating Hong Kong into a seamless infrastructural and economic mesh taking in the entire Pearl River Delta. No longer is Hong Kong a loose collection of islands and other pockets of territory of widely varying scales, landscape conditions and social character, the schemes represent a vision of an antiarchipelago-an attempted undoing of the various archipelagic conditions that have existed, historically and topographically, within the territory of Hong Kong. Instead of a troublesome and complex ecology of dendritic channels and distributaries, alluvial flats and tidal flows, and coastal constellations of crumbling volcanic islands, a vision emerges-sometimes explicit, sometimes tacit-of the vast flatlands of a megacity, as if the entire delta could be transformed into some kind of idealized, endless Los Angeles of urban space. Back in the 1980s, in seeking to convince his prospective patrons in the Guangzhou government of the need for his proposed superhighways, Wu spent fourteen days driving six of them around America's freeway system (Sayer 2006, 64-66). Throughout the latter half of that decade, he was constantly pictured standing in front of maps of the Pearl River Delta, where the bold web of his tollways dominated the older filigree of waterways. Similarly, Leung has woven his case for the East Lantau Metropolis into a narrative that binds the economic survival of Hong Kong into a vision of its integration with its mainland hinterland. If the islandisland relations of the archipelago reflect a transfigurative trope in contrast to those associated with conventional island-mainland relations (Pugh 2013, 20), then Leung's artificial island proposal is one part of a strategy that envisages its literal reversal.

\section{References}

Altink, J. 1987. "Group to Study Airport Proposal." South China Morning Post, April 17.

Anderson, B. 1983. Imagined Communities: Reflections on the Origin and Spread of Nationalism. London: Verso.

Boyden, S., S. Millar, K. Newcombe, and B. O'Neill, eds. 1981. The Ecology of a City and Its People: The Case of Hong Kong. Canberra: Australian National University Press.

Chen, D. 2000. Jiedao weiguan: Xianggang jiedao de dizhi shuxie [A micro-view of the streets the topographical writing of Hong Kong's streets]. Xianggang wenxue (Jul-Aug): 4-14.

Cheung, G. 2003. "Vision of a Speedy Cross-Delta Journey." South China Morning Post, July 29. http://www.scmp.com/article/423220/vision-speedy-cross-delta-journey, accessed December 28, 2014.

Douglas, I. 2011. "The Analysis of Cities as Ecosystems." In The Routledge Handbook of Urban Ecology, edited by I. Douglas, D. Goode, M. Houck, and R. Wang, 17-25. Abingdon, UK: Routledge.

Dung, K. C. 2012. Atlas: The Archaeology of an Imaginary City. Translated by K. C. Dung, A. Hansson, and B. S. McDougall. New York: Columbia University Press.

13. See, for example, Stratford et al. (2011) and Pugh (2013). 
Far Eastern Economic Review. 1987. “The Hongkong Quartet.” March 19, 114.

Fokkema, D. 2011. Perfect Worlds: Utopian Fiction in China and the West. Amsterdam: Amsterdam University Press.

Han, Feng. 2012. "Cultural Landscape: A Chinese Way of Seeing Nature." In Managing Cultural Landscapes, edited by K. Taylor and J. Lennon, 90-108. London: Routledge.

Harte, S. N. and B. Fong. 1987. "New Airport Back on the Agenda." South China Morning Post, June 10 .

Ho, P. Y. 2004. Challenges for an Evolving City: 160 Years of Port and Land Development in Hong Kong, translated by C. S. Johnson. Hong Kong: The Commercial Press.

Hong Kong Government (HKG). 1990. "Review of Gordon Wu Report on Port and Airport Development." Hong Kong: Government Printer, October 2.

- 1991. Hong Kong's Port and Airport Development Strategy: A Foundation for Growth. Hong Kong: Government Printer.

Hong Kong Government Information Services Department (HKGISD). 2015. “Town Planners Map Out Future." January 11. http://www.news.gov.hk/en/categories/inf rastructure/html/ 2015/01/20150109_153251.shtml.

Hopewell Holdings Limited, Cheung Kong (Holdings) Limited, and Hutchison Whampoa Limited. 1987. "Western Harbour-Lantau Strategic Development Project Fact Sheet." January 10.

Irby, R. 1989. "Build an Artificial Island." Letter to the South China Morning Post, July 4.

Kubin, W. 2010. "The Myriad Things: Random Thoughts on Nature in China and the West." In Concepts of Nature: A Chinese-European Cross-Cultural Perspective, edited by H. U. Vogel and G. Dux. Leiden: Brill.

Ledderose, L. 1983. "The Earthly Paradise: Religious Elements in Chinese Landscape Art." In Theories of the Arts in China, edited by S. Bush and C. Murck, 165-83. Princeton, NJ: Princeton University Press.

Leung, C. Y. 2014. "The 2014 Policy Address: Support the Needy, Let Youth Flourish, Unleash Hong Kong's Potential, address to the Hong Kong Legislative Council," January 12. http:// www.policyaddress.gov.hk/2014/eng/pdf/PA2014.pdf, accessed November 22, 2014.

_ _ 2015. "The 2015 Policy Address: Uphold the Rule of Law, Seize the Opportunities, Make the Right Choices; Pursue Democracy, Boost the Economy, Improve People's Livelihood." Address to the Hong Kong Legislative Council, January 14. http://www.policyaddress.gov. hk/2015/eng/pdf/PA2015.pdf, accessed January 15, 2015.

Leys, S. 2013. The Hall of Uselessness: Collected Essays. New York: New York Review of Books.

Li, S. and O. Wong. 2014. "New East Lantau Metropolis Set to Become a Core Business Area." South China Morning Post, January 16. http://www.scmp.com/news/hong-kong/article/ 1406451/new-east-lantau-metropolis-set-become-core-business-area?comment-sort= all\#comments, accessed December 28, 2014.

Murray, M. 1987. "UK to Fund Airport Study." South China Morning Post. January 24.

Ng, A. 1987. "Air and Sea Port Project in the Spotlight." South China Morning Post, July 28.

Pugh, J. 2013. "Island Movements: Thinking with the Archipelago." Island Studies Journal 8 (1): 9-24.

Roy, R. 1989. "Hopewell Lashes out at Government." South China Morning Post. March 16

Sayer, R. 2006. The Man Who Turned the Lights On: Gordon Wu. Hong Kong: Chameleon Press. Sinn, E. 2003. Power and Charity: A Chinese Merchant Elite in Colonial Hong Kong. Oxford: Oxford University Press.
South China Morning Post (SCMP). 1986. "Island Planned for Harbour." August 19.

_ 1987. "Five Years to Completion, Says Hopewell Chief." June 14.

- 1988. "Separating Fact from Supposition on Airport." September 2.

1997. "Wu Sets Homes Challenge." July 17.

Stratford, E., G. Baldacchino, E. McMahon, C. Farbotko, and A. Harwood. 2011. "Envisioning the Archipelago." Island Studies Journal 6 (2): 113-30.

Taylor, C. 2004. Modern Social Imaginaries. Durham, NC: Duke University Press.

Taylor, J. E. 2003. "Nation, Topography, and Historiography: Writing Topographical Histories in Hong Kong." Modern Chinese Literature and Culture 15 (2): 45-74.

Tsang, D. 2003. "Hopewell Set on 50pc Bridge Stake." South China Morning Post, July 17. http:// www.scmp.com/article/421910/hopewell-set-50pc-bridge-stake, accessed December 28, 2014

Torode, G. 1993. "Rival Ports May Speed Expansion." South China Morning Post, October 8.

Verne, J. 1895. Lî́le à helice: Les Milliardaires ridicule. Paris: Collection Hetzel.

Warren, R. 1994. "Report Predicts HK Rents Likely to Hit World High." South China Morning Post, April 6.

Wong, K. S. 2010. "Designing for High-Density Living: High Rise, High Amenity and High Design." In Designing High-Density Cities for Social and Environmental Sustainability, edited by E. Ng, 321-29. London: Earthscan.

Wu, G. 1991. "Contingency Plans for the New Hong Kong Airport." Paper presented at the "Airport Alternatives: We Do Have a Choice!" public seminar at the Hotel Conrad, Hong Kong, organized by the Study Group for Infrastructure Development, May 25

Yao, Y.C. 2001. The Asian Financial Crisis and the Ordeal of Hong Kong. Westport, CT: Quorum Books. 


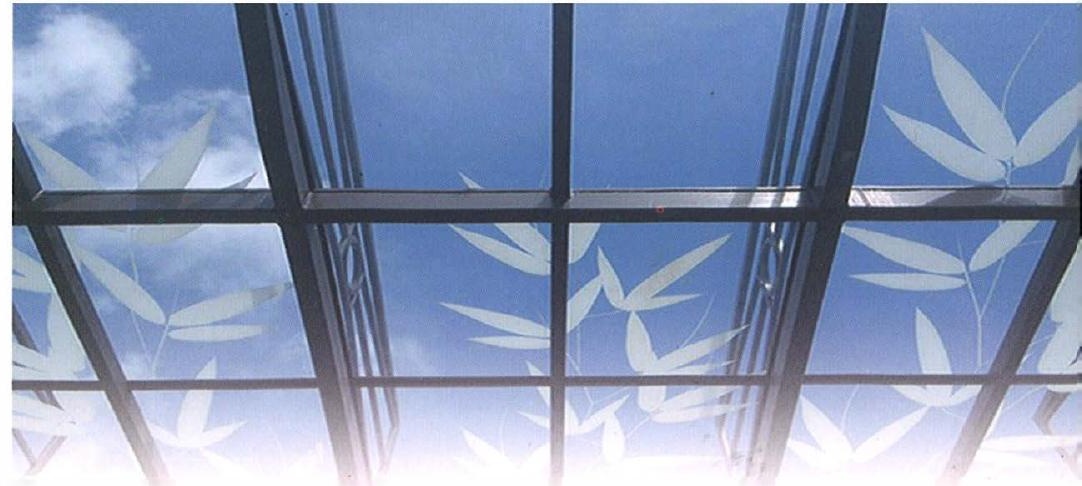

\section{Places of}

Nature

in Eoologies of

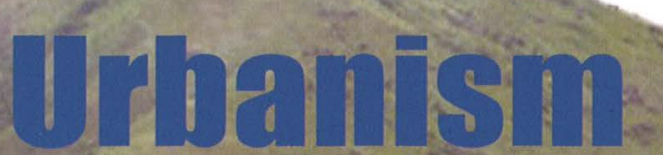

Edited by

Anne Rademacher and

K. Sivaramakrishnan 
"This intellectually adventurous work displays a deep cultural-ethical sensibility in its close attention to geographically variegated forms of place making. A first-rate contribution to urban scholarship on Asia and beyond."

- Vinay K. Gidwani, Department of Geography, Environment and Society and Institute for Global Studies, University of Minnesota

"This volume derives from a several-year collaborative effort to bring scholars from different disciplines together to reflect on the constructed, shifting, and contested meanings of the forward-slash separating Urban/Natures. The essays in this volume are bold, rigorous, original, and sometimes even witty. Without losing track of the intellectual genealogies that enable their collective effort, the authors in Places of Nature in Ecologies of Urbanism give us new tools for imagining urban Asia's possible futures."

—William Glover, Department of History, University of Michigan

If twenty-first-century urbanization is understood as a problem, its regional epicenter is the cities in Asia. Facing unprecedented diversity in scale, scope, and environmental dynamics in the Asian urban experience, scholars will need an approach that can truly capture the significance of place and context. The challenge, as this volume illustrates, can be met by the analytic of ecologies of urbanism. Eschewing a rigid, single ecology, the contributors identify multiple forms of nature-in biophysical, cultural, and political terms - that have discernable impact on power relations and human social action. The case studies in this book-including leopards in Mumbai, a network of tubewells in northern India, an island that grows through reclamation in Hong Kong, and a railway continuum linking Khon Kaen and Bangkok-all attest to the versatility of ecologies of urbanism. Guided by urban processes rather than geopolitical boundaries, Places of Nature in Ecologies of Urbanism offers a picture of urban Asia that is composed of varied ecologies of urbanism.

Anne Rademacher is associate professor of environmental studies and anthropology at New York University.

K. Sivaramakrishnan is Dinakar Singh Professor of India and South Asian Studies, and professor of anthropology and forestry \& environmental studies, at Vale University, where he is also the co-director of the Program in Agrarian Studies.

Cover photos courtesy of

R. Benedito Ferrão and Esther Fung

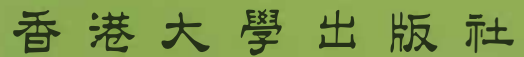

Hong Kong University Press
Ecology / Environmental Studies / Urban Studies

ISBN $978-988-8390-60-1$

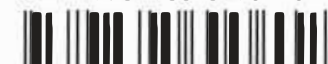
9117898881390601

Printed and bound in llong Kong, China 
Places of Nature in Ecologies of Urbanism 
Places of Nature in Ecologies of Urbanism

Edited by Anne Rademacher and K. Sivaramakrishnan

$$
\begin{aligned}
& \text { NKL } \\
& \text { PRESS } \\
& \text { 香湆大學出服社 }
\end{aligned}
$$


Hong Kong University Press

The University of Hong Kong

Pokfulam Road

Hong Kong

www.hkupress.org

(c) 2017 Hong Kong University Press

ISBN 978-988-8390-59-5 (Hardback)

ISBN 978-988-8390-60-1 (Paperback)

All rights reserved. No portion of this publication may be reproduced or transmitted in any form or by any means, electronic or mechanical, including photocopy, recording, or any information storage or retrieval system, without prior permission in writing from the publisher.

British Library Cataloguing-in-Publication Data

A catalogue record for this book is available from the British Library.

Preface and Acknowledgments

List of Illustrations

Introduction: Places of Nature in Asian Cities and Towns

Anne Rademacher and K. Sivaramakrishnan

1. Inquisitive Legacies: Ecologies of Power and Goan Modernity

R. Benedito Ferrão

2. Eco-Socialism and Green City Making in Postwar Vietnam Christina Schwenkel

3. Urban Leopards Are Good Cartographers: Human-Nonhuman and Spatial Conflicts at Sanjay Gandhi National Park, Mumbai Frédéric Landy

4. Hong Kong's Artificial Anti-Archipelago and the Unnaturing of the Natural

Andrew Toland

5. Tales from the Concrete Cave: Delhi's Birla Temple and the Genealogies of Urban Nature in India Kajri Jain

6. Courts, Public Cultures of Legality, and Urban Ecological Imagination in Delhi

K. Sivaramakrishnan

7. Ecologies of Possibility: Dwelling, Politics, and Government along Khon Kaen's Railway Tracks Eli Elinoff

8. Discrepant Ecologies in a North Indian Qasba: Protected Trees, Degraded River Ann Grodzins Gold 
9. Re-imagining the Indian Underground: A Biography of the Tubewell

Anthony Acciavatti

List of Contributors

Index

\section{Preface and Acknowledgments}

In the summer of 2013, with our first collective effort now in print, ${ }^{1}$ the next phase of our work together began. We decided to send an open call for proposals that would challenge, engage, and broaden the "ecologies of urbanism" conversations we had begun three years previously in Hong Kong. In this next round of discussions, we were keen to expand our thinking beyond India and to pay closer attention to the many scales of urban development, including small cities and towns. To our surprise, we received over one hundred proposals, including at least twenty from talented graduate students-each outlining potentially fruitful ways to refine our thinking and expand our purview. A long and difficult selection process led us to fifteen scholars, and their innovative papers.

With this exceptional group assembled, we gathered in Hong Kong in June 2014. Several graduate students joined us as auditors and commentators, and greatly enriched our conversations. As in the first phase of our Ecologies of Urbanism work, the Hong Kong Institute for Humanities and Social Sciences was our gracious and generous host. With their help, we supplemented our in-conference conversations with a field visit to Macau and extensive explorations of ecologies of urbanism in Hong Kong itself.

The vigorous debates inside and outside our seminar sessions were of great utility as we returned to our writing. New ideas about key concepts, and intellectual challenges introduced by the various case studies, led us to refine our analytical rubric and sharpen our shared insights. Another six months of revisions followed, and a smaller group-of ten scholars and four graduate students selected to make presentations from their own work-reassembled at Yale in February 2015 for further deliberation. Along the way, we invited two special discussants, Joshua Barker and Erik Harms, who gave productive commentaries at our New Haven assembly. The graduate student papers were also thoroughly discussed and encouraged for onward journal submission.

1. Anne Rademacher and K. Sivaramakrishnan (eds), Ecologies of Urbanism in India: Metropolitan Civility and Sustainability (Hong Kong: Hong Kong University Press, 2013). 


\section{Contributors}

Anthony Acciavatti is a postdoctoral fellow in the Agrarian Studies Program at Yale University.

Eli Elinoff is a lecturer in cultural anthropology at the Victoria University of Wellington.

R. Benedito Ferrão is a Mellon faculty fellow in Asian and Middle Eastern studies at William and Mary College.

Ann Grodzins Gold is Thomas J. Watson Professor of Religion and professor of anthropology at Syracuse University.

Kajri Jain is an associate professor in the Department of Visual Studies, University of Toronto, Mississauga.

Frédéric Landy is professor of geography at the University of Paris Ouest-Nanterre, Mosaïques-LAVUE and CEIAS.

Anne Rademacher is associate professor of anthropology and environmental studies at New York University.

Christina Schwenkel is associate professor of anthropology at the University of California, Riverside.

K. Sivaramakrishnan is Dinakar Singh Professor of India and South Asian Studies, professor of anthropology, and professor of forestry and environmental studies at Yale University.

Andrew Toland is a lecturer in landscape architecture at the University of Technology, Sydney. 